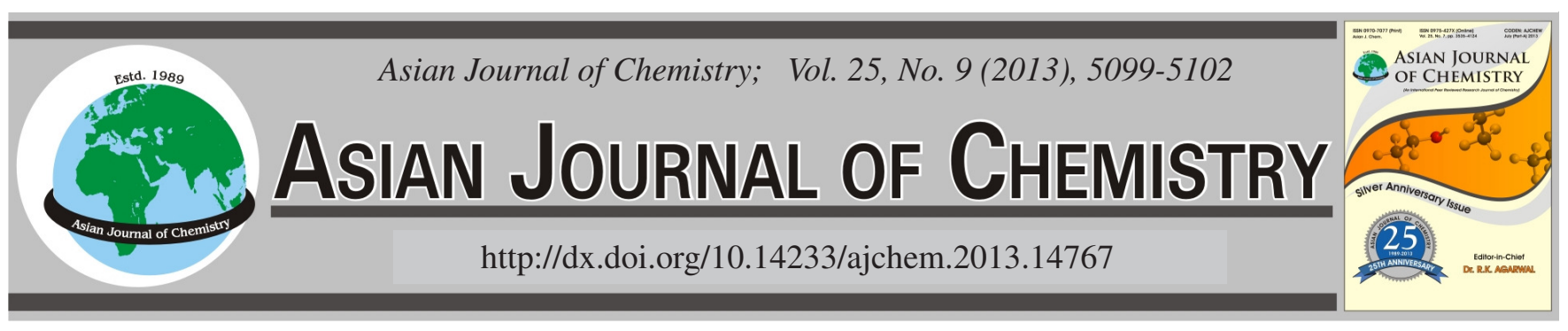

\title{
Adsorption and Release Mechanism of Polypeptide on Magnetic Mesoporous Carbons
}

\author{
Ren-Hong Chen ${ }^{1, *}$, GuO-YING Zhong ${ }^{2}$ and XIU-FANG WANG ${ }^{2}$
}

${ }^{1}$ Guangdong Food and Drug Vocational College, LongDong North Road, TianHe Restrict, Guangzhou 510520, P.R. China

${ }^{2}$ College of Pharmacy, Guangdong Pharmaceutical University, Guangzhou Higher Education Mega Center, Guangzhou 510006, P.R. China

*Corresponding author: Fax: +86 20 37214322; Tel: +86 20 37214322; E-mail: chenrenhong306@163.com

(Received: 2 November 2012;

Accepted: 22 March 2013)

AJC-13147

\begin{abstract}
Magnetic Fe-containing mesoporous carbons with high surface areas and pore volume were synthesized through a simple soft-template route, wherein phenolic resin was used as a carbon precursor, triblock copolymer F127 as a template agent, tetraethyl orthosilicate as a silica precursor and hydrated iron nitrite as an iron source. Dynorphin A (1-13) was selected as polypeptide drug model. The adsorption and release behaviour of dynorphin A (1-13) on magnetic mesoporous carbons were investigated. The adsorption capacity of dynorphin A (1-13) on magnetic mesoporous carbons was mainly the function of the specific surface area, pore volume of the material and the $\mathrm{pH}$ value of solution. The adsorption amount of dynorphin A(1-13) increased with the increase of the specific surface area and pore volume of the materials and $\mathrm{pH}$ value of solution, due to the electrostatic interaction between dynorphin $\mathrm{A}(1-13)$ molecules and carbon, as well as the electrostatic interaction between dynorphin A(1-13) molecules and dynorphin A(1-13) molecules. The two-step release process involved a first fast release and then a slower release. The release behaviour of dynorphin A (1-13) was well correlated with time using a simple exponential equation. The pore size was a crucial factor for the release rate of dynorphin A (1-13), which increased with the increase of pore size.
\end{abstract}

Key Words: Magnetic mesoporous carbon, Dynorphin A (1-13), Adsorption, Release.

\section{INTRODUCTION}

Mesoporous materials with adjustable mesopores (2-50 $\mathrm{nm})$ matched with the dimendions of biological macromolecules such as peptide molecules. Therefore, mesoporous materials have been used as adsorption materials of biomedicine due to its concentrated distribution pore size, large surface area and high pore volume, especially its advantages of excellent biocompatibility, non-toxic and no side effect ${ }^{1-9}$. It is well known that the mesoporous carbon materials were difficult to be separated from the solution. The usual method was by filtration or centrifugation, but this method was complicated, time consuming and relatively expensive price, which limits its practical application ${ }^{10}$. Magnetic mesoporous carbons could be separated easily from the aqueous solution and achieved targeted release in the external magnetic field. Among those magnetic mesoporous carbons (containing $\mathrm{Fe}$, $\mathrm{Co}, \mathrm{Ni}$, or an alloy), iron magnetic mesoporous carbon (Fe/ OMCs) was the most popular and were widely used in biomedicine, catalysis, magnetic storage and water treatment ${ }^{7,11,12}$.

Dynorphin A (1-13) $\left(\mathrm{C}_{75} \mathrm{H}_{126} \mathrm{~N}_{24} \mathrm{O}_{15}\right.$, mw/1604) ${ }^{13}$, which had a bio-polypeptide containing 13 amino acids, had analgesic effect and played a significant role in regulating the cardiovascular and respiratory systems. Drug loading on the support materials was considered to be an effective method to maintain the effective concentration of dynorphin A (1-13) in vivo for a long time and overcome the drawbacks such as chemical and enzymatic degradation, short half-life, etc. Therefore, the researches on the adsorption and release properties of magnetic mesoporous carbons concerning biological polypeptide had important theoretical and practical values. So far, the research on biological polypeptide molecules in the iron magnetic mesoporous carbon load and release has not been covered in the literature.

In the present contribution, magnetic mesoporous carbons (OMCs) with large specific surface and high pore volumes were synthesized by using phenol as carbon precursor, triblock copolymer F127 as a template agent, tetraethyl orthosilicate as a silica precursor and hydrated iron nitrite as an iron source. Dynorphin A (1-13) was used as the biological polypeptide model molecules. The effect on the adsorption and release behaviour of dynorphin A (1-13) by solution concentration, $\mathrm{pH}$ and pore structure of the carbon materials were investigated.

\section{EXPERIMENTAL}

Triblock poly(ethylene oxide)- $\beta$-poly(propylene oxide)bpoly(ethylene oxide) copolymer Pluronic F127 ( $\mathrm{mw}=12600$, 
$\mathrm{PEO}_{106} \mathrm{PPO}_{70} \mathrm{PEO}_{106}$ ) was purchased from Aldrich Corp. Dynorphin A (1-13) was purchased from Sinoasis Pharmaceuticals Inc(Guangzhou). Trifluoroacetic acid and acetonitrile (chromatographic pure) were purchased from Sigma and Fisher, respectively. The other chemicals were A.R. and were used as received without any further purification.

Magnetic Fe-containing mesoporous carbons were synthesized by co-assembly of multi-components. The typical synthesis procedure was as follows. Briefly, $1.6 \mathrm{~g}$ of F127 and $0.17 \mathrm{~g}$ of hydrated iron nitrite were dissolved in $8 \mathrm{~g}$ of ethanol solution (salmon pink). $1 \mathrm{~g}$ of hydrochloric acid (0.2 M), $2 \mathrm{~g}$ of tetraethyl orthosilicate and $5 \mathrm{~g}$ of phenolic resin/ethanol solution were added drop wise successively ${ }^{14,15}$. After mixing $2 \mathrm{~h}$, the blue mixture was placed in a petri dish at room temperature to evaporate the solvent. The resulting solid was solidified in an oven at $100{ }^{\circ} \mathrm{C}$ for $24 \mathrm{~h}$ (brown). The solid composite was carbonized in a tubular furnace (KTL1400) under flowing $\mathrm{N}_{2}$ atmosphere at $800{ }^{\circ} \mathrm{C}$ (heating rate $1{ }^{\circ} \mathrm{C} /$ $\min$ ) for $2 \mathrm{~h}$. The silica template was removed by dissolving the silica/carbon composite in $80^{\circ} \mathrm{C} 1 \mathrm{M} \mathrm{NaOH}$ water/ethanol solution $(1: 1$, vol \%) for more than $24 \mathrm{~h}$. After filtration, the material was washed with deionized water until $\mathrm{pH}=7$ and then was dried at $60{ }^{\circ} \mathrm{C}$ for $24 \mathrm{~h}$ under vacuum. The products were labeled as II-C. I-C and III-C were also synthesized by varying the weight of $\mathrm{Fe}\left(\mathrm{NO}_{3}\right)_{2} \cdot 9 \mathrm{H}_{2} \mathrm{O}$, where, I and III referred to $0.096 \mathrm{~g}$ and $0.26 \mathrm{~g}$ of $\mathrm{Fe}\left(\mathrm{NO}_{3}\right)_{2} \cdot 9 \mathrm{H}_{2} \mathrm{O}$, respectively.

For the adsorption and release of dynorphin A(1-13) experiment, 30, 45, 60, 75, 90, $120 \mathrm{mg} / \mathrm{L}$ dynorphin A(1-13) in phosphate solution $(\mathrm{pH}=7.0)$ solution were prepared. Then $3 \mathrm{mg}$ of mesoporous carbon materials I-C, II-C and III-C were added into the above solution at room temperature for $48 \mathrm{~h}$. $10 \mu \mathrm{L}$ of supernatant was analyzed by HPLC, the adsorption capacity of dynorphin A(1-13) on magnetic OMCs was determined by the change of the concentration before and after adsorption. The $\mathrm{pH}$ of the phosphate solution $(150 \mathrm{mg} / \mathrm{L})$ was varied from 6 to 9.2, 10, respectively to investigate the influence of $\mathrm{pH}$ value on the adsorption and release behaviour of dynorphin A (1-13) with the same amount of the mesoporous carbon materials and the same adsorption procedure. For the drug release research, drug-loaded magnetic mesoporous carbon was added to $10 \mathrm{~mL}$ of phosphate buffer solution $(\mathrm{pH}$ $=7.0$ ), follow by stirring at $37^{\circ} \mathrm{C}, 1 \mathrm{~mL}$ of samples were removed at given time intervals while complementing phosphate solution $(\mathrm{pH}=7.0) 1 \mathrm{~mL}$ and analyzed by HPLC.

Characterization: Nitrogen adsorption isotherms were measured with Micromeritics Tristar 3020 volumetric adsorption analyzer at $77 \mathrm{~K}$. The specific surface area of the samples was calculated by using the BET method. The pore size distributions were derived from the adsorption branches of isotherms by using the Barett-Joyner-Halenda $(\mathrm{BJH})$ model and the total pore volumes $\left(\mathrm{V}_{\mathrm{t}}\right)$ were estimated from the adsorption amount at a relative pressure $\mathrm{P} / \mathrm{P}_{0}$ of 0.99 . Adsorption and release behaviour of dynorphin A (1-13) on mesoporous material was detected by high-performance liquid chromatograph (HPLC, Agilent 1200) at $210 \mathrm{~nm}$. Gradient outflow of solution A was acetonitrile containing $0.1 \%$ trifluoroacetic acid and solution B was ultrapure water containing $0.1 \%$ trifluoroacetic acid. The effluent rate was $1 \mathrm{~mL} / \mathrm{min}$. The gradient program was that the concentration of A solution was changed from $5 \%$ to $45 \%$ within $35 \mathrm{~min}$, then washed column by $5 \%$ solution A for $10 \mathrm{~min}$. The retention time of dynorphin A (1-13) was $22.3 \mathrm{~min}$.

\section{RESULTS AND DISCUSSION}

The nitrogen sorption isotherms of the samples (Fig. 1A) showed representative type-IV curves with $\mathrm{H} 1$ hysteresis loops. The sharp inflections of the relative pressures in the range of $\mathrm{P} / \mathrm{P}_{0}=0.5-0.8$ indicated the reservation of a typical mesoporous material. The parameters were listed in Table-1. The specific surface area and the pore volumes for I-C, II-C and III-C decreased with the increasing of metal nitrates loading, which might arise from the higher density of iron. The pore sizes of I-C, II-C and III-C (5.3, 5.5, $6.4 \mathrm{~nm}$, Fig. 1B) increased with the increasing of metal nitrates loading, which might be due to the consumption of the carbon atoms surrounding metal nitrates during the reduction reaction.

TABLE-1

STRUCTURAL PARAMETERS FOR MAGNETIC MESOPOROUS CARBONS AND THE FITTED PARAMETERS BY EXPONENTIAL EQUATION

\begin{tabular}{ccccccc}
\hline Sample & $\mathrm{S}_{\mathrm{BET}}\left(\mathrm{m}^{2} \mathrm{~g}^{-1}\right)$ & $\mathrm{V}_{\mathrm{t}}\left(\mathrm{cm}^{3} \mathrm{~g}^{-1}\right)$ & $\mathrm{D}_{\mathrm{p}}(\mathrm{nm})$ & $\mathrm{A}$ & $\mathrm{K}$ & $\delta$ \\
\hline I-C & 1006 & 1.29 & 5.3 & 13.3 & 0.04 & 0.10 \\
II-C & 756 & 0.83 & 5.5 & 29.8 & 0.06 & 0.06 \\
III-C & 629 & 0.64 & 6.4 & 43.5 & 0.04 & 0.05 \\
\hline
\end{tabular}
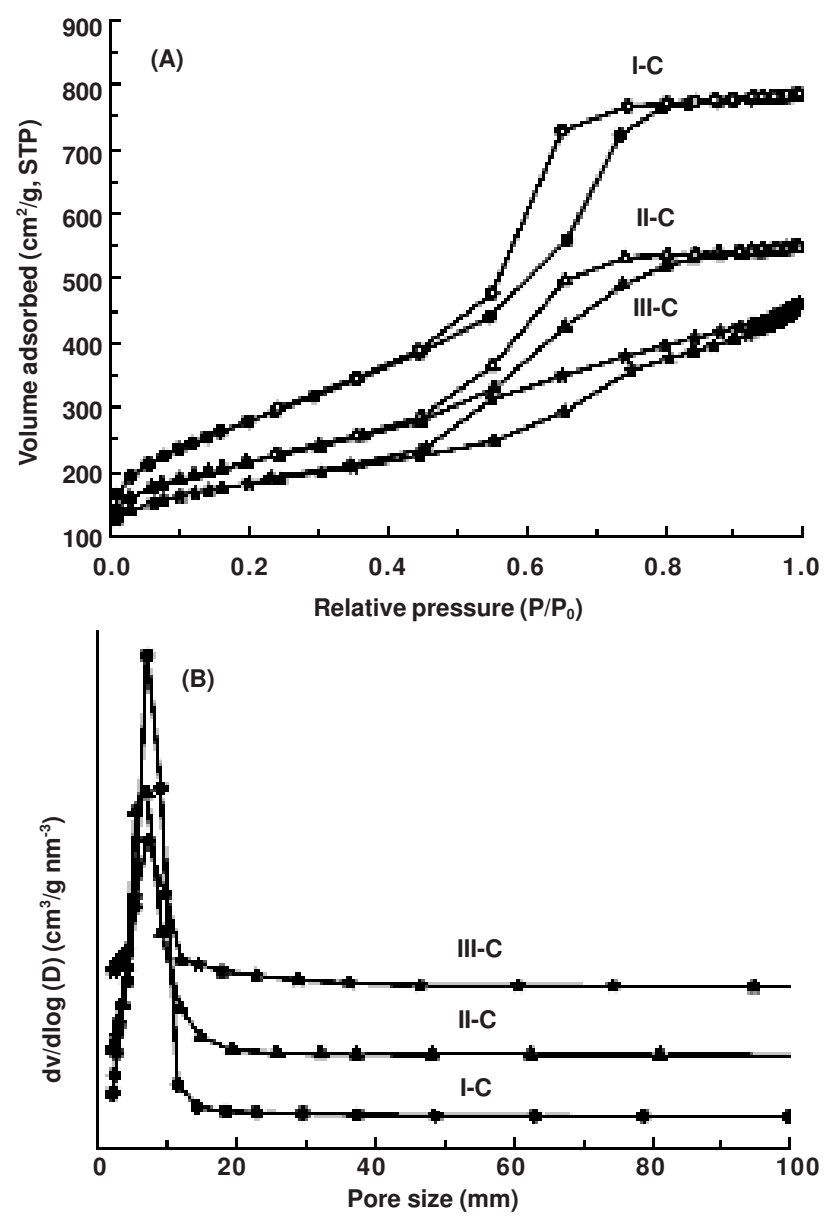

Fig. 1. Nitrogen sorption isotherms (A) and pore size distributions (B) of the materials 
Fig. 2 showed that the amount of dynorphin A (1-13) adsorption increased with the increase of the equilibrium solution concentration, which might be due to the reason that the increase of the concentration of dynorphin A (1-13) facilitated the diffusion of the dynorphin A (1-13) molecules to the carbon surface and mesopores of materials. The specific surface area and the pore volumes for I-C were $1006 \mathrm{~cm}^{2} / \mathrm{g}$ and $1.29 \mathrm{~cm}^{3} / \mathrm{g}$, respectively. The specific surface area and the pore volumes for I-C were $629 \mathrm{~cm}^{2} / \mathrm{g}$ and $0.641 .29 \mathrm{~cm}^{3} / \mathrm{g}$, respectively. The experimental results indicated that the adsorption amount increased with the increase of the specific surface area and pore volume of the materials.

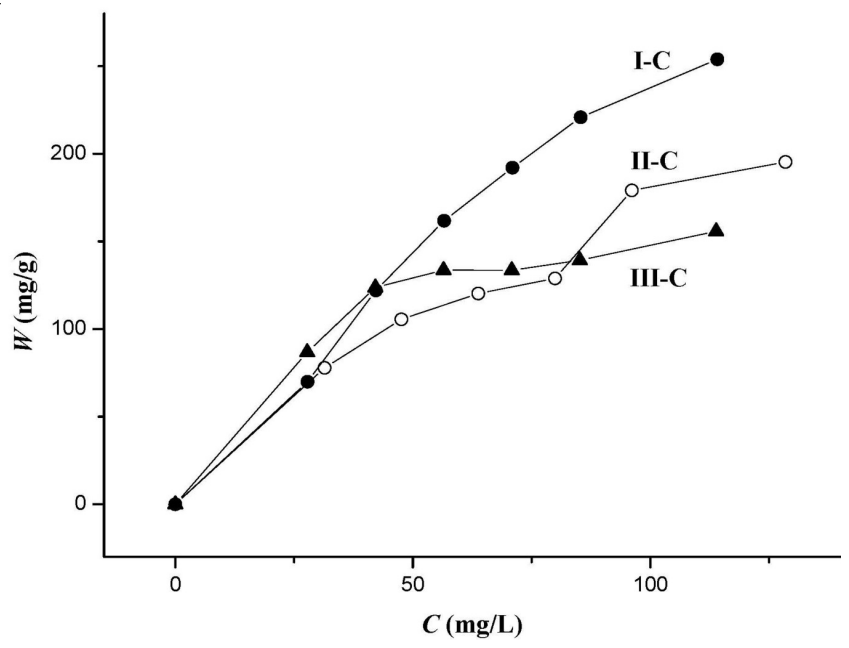

Fig. 2. Adsorption curve of dynorphin A (1-13) on the materials

The molecular size of dynorphin A (1-13) was $4 \times 1.7 \times 1$ $\mathrm{nm}$, which could be easily filled into the mesopores of I-C, II-C and III-C with a pore size of 5.3-6.4 nm. The effect of specific surface area and the pore volumes was more important. High specific surface area and large pore volumes could increase the adsorption capacity of dynorphin A (1-13).

Fig. 3 showed that the adsorption amount of dynorphin A (1-13) on the materials increased with the increase of the $\mathrm{pH}$ values, which might be due to the electrostatic interactions between carbon and dynorphin A (1-13) molecules and between the free dynorphin A (1-13) molecules and the adsorbed dynorphin A (1-13) 10. The pI of carbon materials and dynorphin A (1-13) were 3.2 and 11.7, respectively. In the present study, the $\mathrm{pH}$ value of the solution was between the $\mathrm{pI}$ of carbon and dynorphin A (1-13) molecules. It was clear that there was an electrostatic interaction between the negatively charged carbon surface and the positively charged dynorphin A (1-13) molecules, which was favourable to the adsorption of dynorphin A (1-13) on carbon materials. Whereas, there also existed electrostatic exclusion interactions between the free positively charged dynorphin A (1-13) molecules and the adsorbed dynorphin A (1-13) molecules on the surface of carbon materials, thus enlarging the distance and space of dynorphin A (1-13) molecules which were adsorbed on the surface. It was unfavourable to the tight accumulation of dynorphin A (1-13) molecules and the adsorption amount decreased as a result. With the increasing of the $\mathrm{pH}$ values, the net positive electric density of the dynorphin A (1-13) mole- cules reduced. And the mutual repulsion between them was also reduced, thus resulting in the increase of adsorption amount. The closer the $\mathrm{pH}$ values to $\mathrm{pI}$, the higher the carbon adsorption amount of dynorphin A (1-13) molecules.

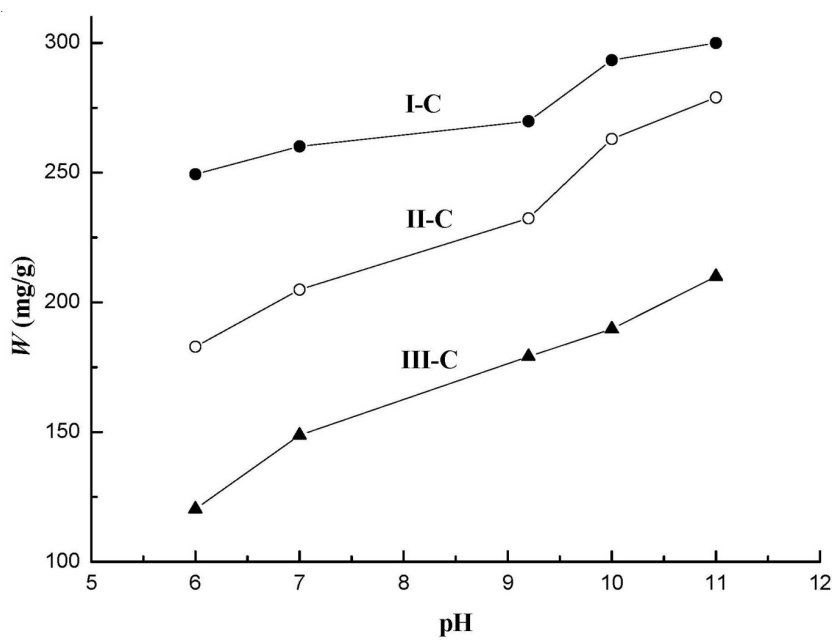

Fig. 3. Influence of $\mathrm{pH}$ value on adsorption of materials

Fig. 4 showed the release curves for dynorphin A(1-13) on the synthesized materials. The release process of dynorphin A (1-13) on the mesoporous carbon materials involved mainly two steps, e.g., first a fast release and then a slower release delivery process. As was well known, only when the dissolution media were in contact with the drug, could the drug be released to the media. The fast-release stage was mainly due to the release of dynorphin A (1-13) absorbed on the surface of magnetic mesoporous carbons, which could be quickly released in the media solvent. The sustained release stage was

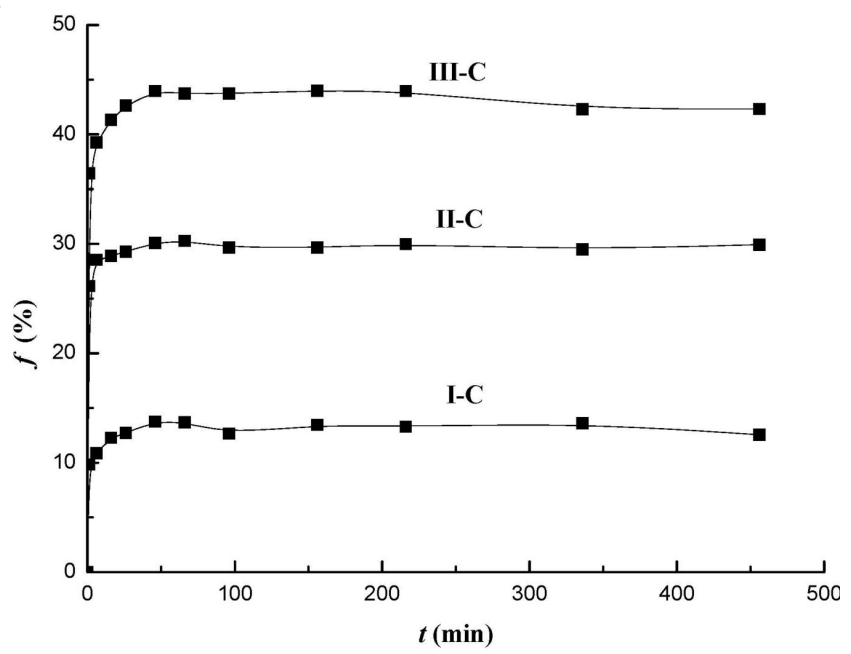

Fig. 4. Release curves for dynorphin A(1-13) on the materials

mainly the release of drugs inside the pores. And only when the dissolution media penetrated into the pores of material, could dynorphin A (1-13) molecules be released within the dissolution media, which resulted in a slow release of drug. This release behaviour was described by using a simple exponential equation ${ }^{16}$.

$$
\mathrm{f}=\mathrm{A}\left(1-\mathrm{e}^{-\mathrm{kt}}\right)^{\delta}
$$


where, $\mathrm{f}$ was the cumulative release fraction; A was the maximum cumulative release of the peptide fraction; $\mathrm{k}$ was the release rate constant relative to the solvent accessibility and diffusion coefficient. $\delta$ was the empirical non-ideality factor that was associated with biological peptides adsorbed on the outer surface. The values of $\delta$ were usually between 0 and 1.0. Zero (0) denoted the initial burst release and one (1) represent that the release process obeyed the first-order ideal release kinetics. The fitted parameters are also listed in Table- 1 and the correlation coefficient was greater than 0.99 .

As shown in Fig. 1, the $\delta$ value for I-C was relatively large, which indicated that a large percentage of the peptide drugs was released through the internal pores. It was noted in the range of the time studies, the total percentage of the release of peptide dynorphin A (1-13) was relatively low, indicating that some peptides still remained in the pores of materials. The smaller the value of $\delta$, the greater percentage of peptide released from the outer surface through the material. The reason was mainly due to the increased magnetic particles and the decreased ordering of the materials, which hindered the release of polypeptide molecule through the pore channels of mesoporous carbons (II-C, III-C). All of the three materials were not completely released, which was due to the following two reasons. On the one hand, the hydrophobic properties of mesoporous carbons made it difficult for the deeper inner surface of the material to be soaked, which led to the result that part of the molecules of dynorphin A (1-13) could not be released. On the other hand, the electrostatic attraction between mesoporous materials and dynorphin A (1-13) molecules also made it difficult for the molecules of dynorphin A (1-13) to be released in a limited period of time.

\section{Conclusion}

Magnetic mesoporous carbons were synthesized. The adsorption amount of dynorphin A (1-13) on magnetic mesoporous carbons increased with the increasing of specific surface area and pore volume of the materials. In the ranges of $\mathrm{pH}$ values studied. The adsorption amount of dynorphin $\mathrm{A}$
(1-13) on magnetic mesoporous carbons increased with the increase of the $\mathrm{pH}$ values, which was mainly due to electrostatic interaction between molecules of dynorphin A (1-13) and carbon materials. The release process of dynorphin A (1-13) on the magnetic mesoporous carbons involved mainly two steps, first a fast release and then a slower release process. This release behaviour could be well described by a simple exponential equation. The release rate of dynorphin A (1-13) increased with the increase of specific surface area and pore volume and decreased with the increase of the pore sizes of the magnetic mesoporous carbons.

\section{ACKNOWLEDGEMENTS}

The authors acknowledge the National Science Foundation of China (50802017) and Guangzhou Scientific and technological planned project (2011J4100016).

\section{REFERENCES}

1. Y. Fang, D. Gu, Y. Zou and D.Y. Zhao, Angew. Chem. Int. Ed., 49, 7987 (2010).

2. Y. Tian, P. Liu, X.F. Wang and H.S. Lin, Chem. Eng. J., 171, 1263 (2011).

3. A. Vinu, M. Miyahara and K. Ariga, J. Phys. Chem. B, 109, 6436 (2005).

4. L.C. Sang, A. Vinu and M.O. Coppens, Langmuir, 27, 13828 (2011).

5. L.M. Guo, L.X. Zhang and J.L. Shi, Chem. Commun., 46, 7127 (2010).

6. Y. Tian, P. Liu and X.F. Wang, Mater. Lett., 82, 19 (2012).

7. X.F. Wang, P. Liu, Y. Tian and L.Q. Zang, Micropor. Mesopor. Mater., 145, 98 (2011).

8. X.F. Wang, P. Liu and Y. Tian, Micropor. Mesopor. Mater., 142, 334 (2011).

9. X.F. Wang, P. Liu and Y. Tian, J. Solid State Chem., 184, 1571 (2011).

10. Y.P. Zhai, Y.Q. Dou, X.X. Liu, B. Tu and D.Y. Zhao, J. Mater. Chem., 19, 3292 (2009).

11. J.S. Li, J. Gu, H.J. Li and X.Y. Sun, Micropor. Mesopor. Mater., 128, 144 (2010).

12. Y. Tian, X.F. Wang and Y.F. Pan, J. Hazard. Mater, 213-214, 361 (2012).

13. X.F. Wang and Y. Tian, Chinese J. Chem., 27, 2090 (2009).

14. Y. Meng, D. Gu, F.Q. Zhang, Y.F. Shi and D.Y. Zhao, Angew. Chem. Int. Ed., 44, 7053 (2005).

15. Y. Tian, G. Y. Zhong, X.F. Wang and H.S. Lin, CIESC J., 63, 4082 (2012).

16. F. Balas, M. Manzano, M. Colilla and M. Vallet-Regi, Acta Biomater., 4, 514 (2008) 